\title{
Some Aspects of Reproduction in the Pointed-snout Dogfish Squalus japonicus Taken off Nagasaki and Choshi*1
}

\author{
Chetsung Chen*2, Toru TANIUCHI ${ }^{* 3}$, and Yukio NOSE*9
}

(Received April 24, 1981)

\begin{abstract}
Specimens of the pointed-snout dogfish Squalus japonicus taken off Nagasaki and Choshi, were investigated to study its reproduction. Specimens from Choshi were larger in the size at maturity as well as in the maximum size than those from Nagasaki. The size at first maturity for females was $560-579 \mathrm{~mm}$ in Nagasaki and $740-759 \mathrm{~mm}$ in Choshi. Maximum lengths were greater by $14 \mathrm{~cm}$ for males and $19 \mathrm{~cm}$ for females in Choshi than in Nagasaki. Testis weights and clasper lengths showed a rapid increase with onset of maturity. The gestation period was estimated to be roughly one year since both full-term embryos and fertilized eggs occurred in the same period. Litter size ranged from 2 to 8 for each region but average litter size was 3.9 in Nagasaki and 5.3 in Choshi. Litter size increased with size of the parent. A difference was also noted in the average number of ovarian eggs per adult female between the two regions (4.4 in Nagasaki and 6.6 in Choshi). Ova usually outnumbered embryos and showed a similar growth pattern to embryos. The ratio of males to females in embryos was approximately $1: 1$ as a whole in both regions.
\end{abstract}

The reproductive mode of sharks of the genus Squalus is aplacental type of viviparity according to the categories given by Wourms. ${ }^{11}$ Embryos are provided with nutrition from yolk reserves. In the spiny dogfish $S$. acanthias embryos grow up in the uteri of the parent for about two years, showing approximately similar gestation period to the elephant. Litter size is very small ranging from 7 to 22 (average 12.4) around Japan, ${ }^{21}$ from 2 to 16 (average 6.6) in British Columbia Waters, ${ }^{31}$ and from 1 to 11 (mostly 2 to 4 ) in the eastern North Atlantic.4) The reproductive rate, which is a basic parameter for the estimation of population growth, has been calculated for the spiny dogfish in the North Sea ${ }^{b 1}$ and in British Columbia Waters. ${ }^{\text {") }}$ Thus, extensive studies have demonstrated that the spiny dogfish possesses a peculiar reproductive strategy of low fecundity and large gestation period. However, reproduction of other Squalus species except for $S$. brevirostris ${ }^{7,8)}$ has scarcely been reported probably because they are not direct subjects of commercial fisheries.

There are five species of Squalus around Japan according to a recent revision of the $S$. blainville group." Among them, the pointed-snout dog- fish $S$. japonicus occurs widely from central Japan to Kyushu and Taiwan and is one of the most abundant species." This paper reports some aspects of reproduction in $S$. japonicus taken off Nagasaki and Choshi located in southern and central Japan respectively.

\section{Materials and Methods}

Specimens were collected in fish markets in Nagasaki and Choshi. They were caught with bottom longline and trawl net in the depths of $150-300 \mathrm{~m}$ off Choshi and chiefly with bottom longline in the depths of 120-300 m off Nagasaki. Date, locality, and the number of specimens examined are indicated in Table 1. Small specimens were not available because they have little commercial value. The specimens were examined in fresh state.

Maturity stages of females were classified into three categories, immature, maturing, and mature. "Immature" was defined as sharks having ova less than $5 \mathrm{~mm}$ in diameter in the ovary and threadlike uteri, "maturing" as those having both ova larger than $10 \mathrm{~mm}$ in diameter and relatively ex-

\footnotetext{
*1 This study was supported in part by a Grant-in-Aid for Scientific Research from the Ministry of Education of Japan (Grant No. 036006).

*2 Department of Fisheries, National Taiwan College of Marine Science and Technology, Keelung, Taiwan, ROC (陳哲㙏：国立台湾海洋学院漁業学系).

*8 Faculty of Agriculture, University of Tokyo, Bunkyo, Tokyo 113 (谷内 透・能勢幸雄：東京大学费学 部).
} 
Table 1. Date, locality, and number of specimens examined in this study

\begin{tabular}{lrrrr}
\hline \multicolumn{1}{c}{ Locality } & $\left.\begin{array}{c}\text { Nagasaki } \\
125^{\circ}-130^{\circ} \mathrm{E} \\
28^{\circ}-34^{\circ} \mathrm{N}\end{array}\right)$ & \multicolumn{2}{c}{$\begin{array}{c}\text { Choshi } \\
\left(\begin{array}{l}141^{\circ}-141^{\circ} 20^{\prime} \mathrm{E} \\
35^{\circ} 30^{\prime}-36^{\circ} \mathrm{N}\end{array}\right)\end{array}$} \\
$\begin{array}{l}\text { Sampling duration Nov.74-Nov.'76 } \\
\text { Number of } \\
\text { specimens }\end{array}$ & $\begin{array}{l}\text { Male } \\
\text { Oct.'74-Oct.'76 }\end{array}$ & Female & Male & Female \\
\hline January & 1 & 40 & & \\
February & 4 & 62 & 1 & 3 \\
March & 16 & 18 & 2 & 13 \\
April & 1 & 46 & 3 & 11 \\
May & 82 & 22 & 5 & 15 \\
June & 14 & 34 & 39 & 63 \\
July & & 27 & & \\
August & & 33 & & \\
September & & 52 & 1 & \\
October & 16 & 104 & 2 & 3 \\
November & 31 & 14 & 7 & 20 \\
December & 6 & 47 & 2 & 15 \\
$\quad$ Total & 171 & 499 & 62 & 143 \\
\hline
\end{tabular}

panded uteri, and "mature" as those having either ova larger than $10 \mathrm{~mm}$ in diameter in the ovary or uteri containing embryos or fertilized eggs. The size of ovarian eggs was the average diameter of all eggs in both ovaries. Maturity of males was estimated on the basis of the presence of sperm in the spermduct and the rigidity of claspers. Clapser length was measured from cloaca to the tip of the clasper. Full-term embryos were judged by the absence of both external and internal yolk sacs. Ova immediately before ovulation was considered as those larger than $30 \mathrm{~mm}$ in diameter before or just after parturition of embryos. Litter size includes the number of fertilized eggs as well as the number of embryos.

\section{Results}

\section{Maturity}

A large difference existed in the size at first maturity between Nagasaki and Choshi specimens (Table 2). Females reached their first maturity at $560-579 \mathrm{~mm}$ in Nagasaki and $740-759 \mathrm{~mm}$ in Choshi. Approximately a difference of $18 \mathrm{~cm} \mathrm{ex-}$ isted between the two regions. Fifty percent maturity was reached at lengths of $660-679 \mathrm{~mm}$ in Nagasaki and $820-839 \mathrm{~mm}$ in Choshi. All female specimens from Nagasaki except one had attained maturity at a length of $66 \mathrm{~cm}$ while all females from Choshi had reached maturity at

Table 2. Number of specimens taken from Nagasaki and Choshi

\begin{tabular}{|c|c|c|c|c|c|c|c|c|c|c|}
\hline \multirow{2}{*}{$\begin{array}{c}\text { Total length } \\
\text { of specimens } \\
(\mathrm{mm})\end{array}$} & \multicolumn{10}{|c|}{ Number of specimens } \\
\hline & \multicolumn{2}{|c|}{ Nagasaki (Male) } & \multicolumn{2}{|c|}{ Choshi (Male) } & \multicolumn{3}{|c|}{$\begin{array}{c}\text { Nagasaki (Female) } \\
\text { Immature Maturing Mature }\end{array}$} & \multicolumn{3}{|c|}{$\begin{array}{c}\text { Choshi (Female) } \\
\text { Immature Maturing Mature }\end{array}$} \\
\hline $300-399$ & 3 & & 2 & & & & & & & \\
\hline $400-439$ & 3 & & & & & & & & & \\
\hline $440-499$ & 5 & & & & 5 & & & & & \\
\hline $500-519$ & 4 & & & & 4 & & & & & \\
\hline $520-539$ & 14 & 2 & & & 4 & & & & & \\
\hline $540-559$ & 19 & 11 & & & 11 & & & & & \\
\hline $560-579$ & 9 & 33 & 1 & & 5 & 2 & 1 & & & \\
\hline $580-599$ & 5 & 24 & & & & 14 & 8 & & & \\
\hline $600-619$ & 5 & 18 & 1 & 1 & & 16 & 27 & & & \\
\hline $620-639$ & 1 & 6 & 1 & 1 & & 3 & 50 & & & \\
\hline $640-659$ & & 2 & 1 & 2 & & 4 & 59 & & & \\
\hline $660-679$ & & & 1 & 8 & & & 81 & 6 & & \\
\hline $680-699$ & & & & 13 & & & 74 & 12 & & \\
\hline $700-719$ & & & & 12 & 1 & & 74 & 9 & & \\
\hline $720-739$ & & & & 6 & & & 29 & 2 & & \\
\hline $740-759$ & & & & 2 & & & 9 & & 2 & 4 \\
\hline $760-779$ & & & & 1 & & & 1 & & 4 & 9 \\
\hline $780-799$ & & & & & & & & & 2 & 7 \\
\hline $800-819$ & & & & & & & & & & 16 \\
\hline $820-839$ & & & & & & & & & & 12 \\
\hline $840-859$ & & & & & & & & & & 6 \\
\hline $860-879$ & & & & & & & & & & 9 \\
\hline $880-899$ & & & & & & & & & & 3 \\
\hline $900-919$ & & & & & & & & & & 4 \\
\hline Total & 68 & 96 & 7 & 46 & 30 & 39 & 413 & 29 & 8 & 70 \\
\hline
\end{tabular}




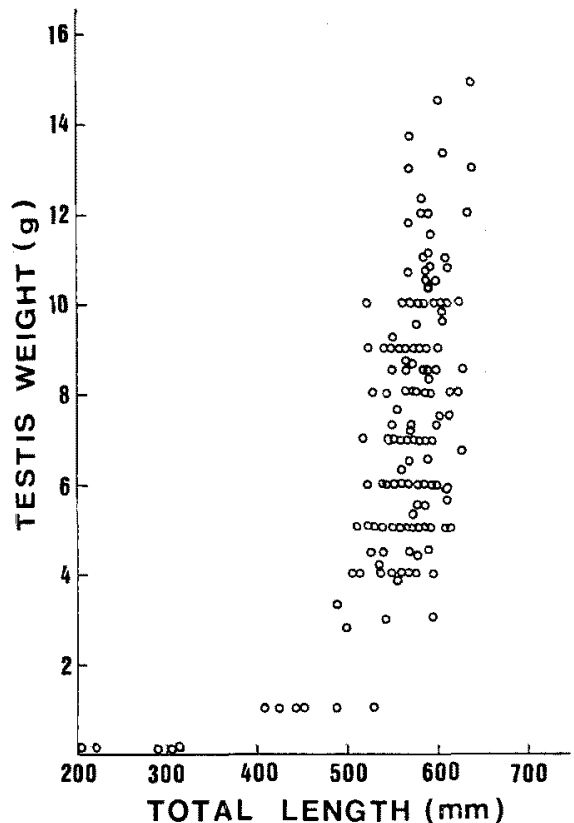

Fig. 1. Relationship between total length and testis weight in $S$. japonicus collected from Nagasaki.

$80 \mathrm{~cm}$. Maturing condition was found between $560-749 \mathrm{~mm}$ in Nagasaki and $740-799 \mathrm{~mm}$ in Choshi. The maximum size of female specimens in the samples was also larger in Choshi $(950 \mathrm{~mm})$ than in Nagasaki (758 mm).

The same difference was found in male specimens. Males reached maturity at a length of about $50 \mathrm{~cm}$ in Nagasaki but did not attain maturity until $70 \mathrm{~cm}$ in Choshi. Similarly, the maximum size of males in the samples was greater in Choshi $(700 \mathrm{~mm})$ than in Nagasaki $(640 \mathrm{~mm})$. Males became mature at a smaller size than females (Table 2).

The relationship between total length and testis weight (Fig. 1) shows that testis weight increased abruptly at a length of $50-55 \mathrm{~cm}$ in Nagasaki. In Choshi, testis weight showed a rapid increase at a length of $60-65 \mathrm{~cm}$, although the small specimens were very few. The relationship between total length and clasper length also demonstrates that the claspers grew rapidly when the sharks reached about $50 \mathrm{~cm}$ in Nagasaki (Fig. 2). In Choshi, this size was about $60 \mathrm{~cm}$. Thus, both testis weight and clasper length showed rapid increases with onset of maturity and can be used as indices of maturity for male specimens of this species.

\section{Growth of Embryos and Eggs}

Each fertilized egg is enveloped in a membrane which develops as an embryonic membrane after

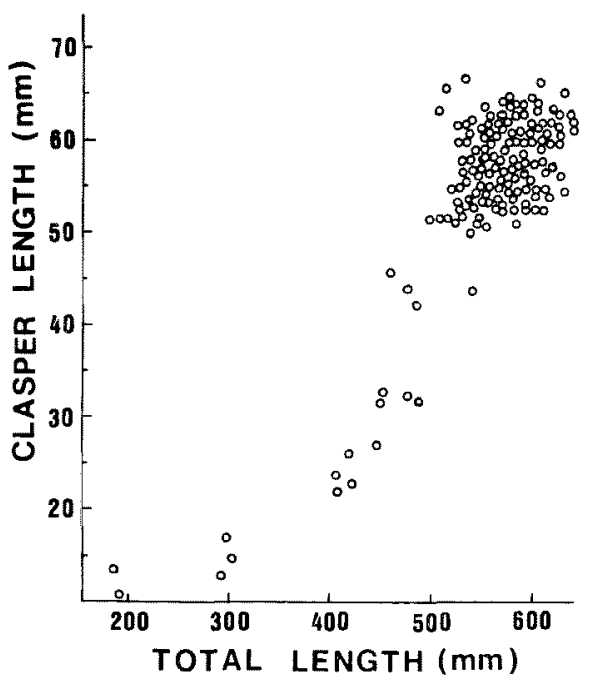

Fig. 2. Relationship between total length and clasper length in $S$. japonicus collected from Nagasaki.

hatching from an egg. Frequency occurrence of fertilized eggs is indicated in Fig. 3, together with monthly frequency distributions of embryos in Nagasaki. Fertilized eggs and embryos less than $40 \mathrm{~mm}$ in total length which seemed to be in a stage after hatching out from fertilized eggs were observed from January to May in Nagasaki. The embryos reached $41-60 \mathrm{~mm}$ in June, $61-100 \mathrm{~mm}$ in August and September, 101-180 mm in October and $161-220 \mathrm{~mm}$ in November and December, although considerable variation existed in size distributions of embryos. Embryos ranging from 191 to $235 \mathrm{~mm}$, which occurred from January to May, were regarded to be full-term embryos because both external and internal yolk sacs were almost fully absorbed. At this time, we frequently observed remains of embryonic membranes in the uteri of adult females without embryos. These facts suggest that the reproductive season lasts from January to May. Since fertilized eggs and embryos soon after hatching out of eggs were found during that time, gestation period of this species was estimated to be roughly one year. However, monthly gonad indices of male specimens showed no marked seasonal change in both regions, so that gonad index was not a useful character as means of the estimation for the mating season. It is probable that females give birth to young each year because fertilized eggs were found in the uteri of females which apparently had just delivered embryos. The same trend of growth of embryos was recognizable in the specimens from Choshi, 


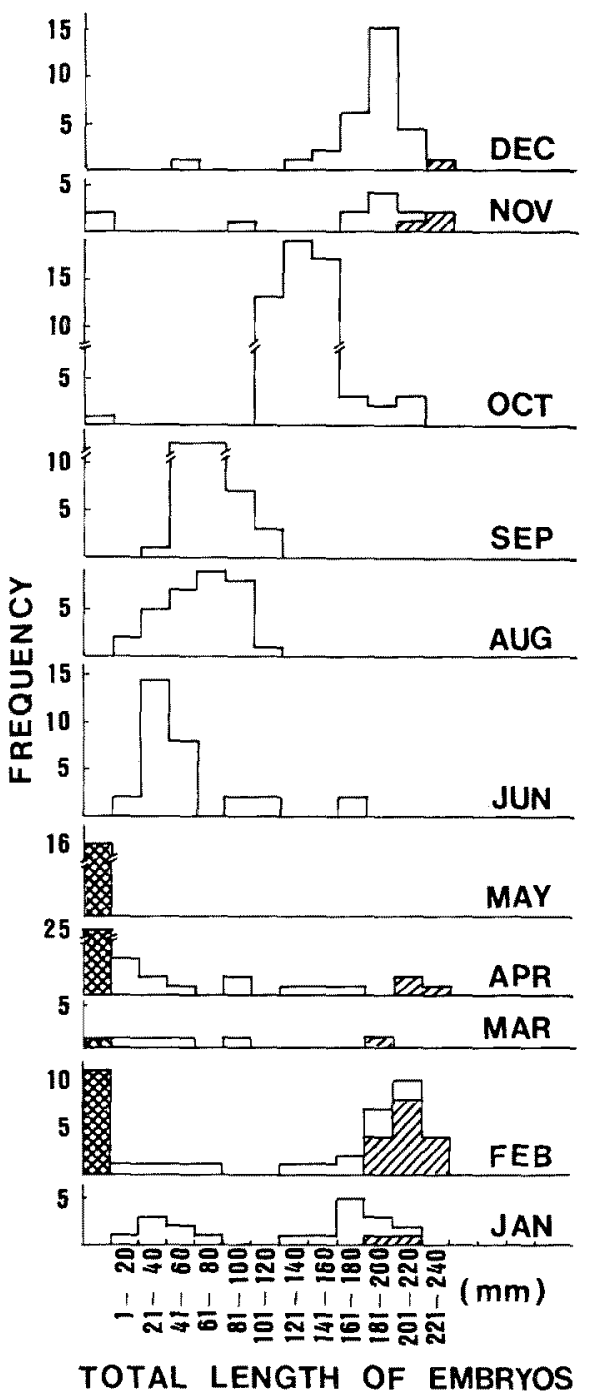

Fig. 3. Monthly length frequency distributions of embryos in S. japonicus collected from Nagasaki. Oblique shaded histogram shows near-term embryos and crossed one indicates fertilized eggs.

although samples of gravid females were not sufficient. Full-term embryos in Choshi ranged from 206 to $240 \mathrm{~mm}$ in total length. No marked difference was observed in the size of full-term embryos between the two regions. Statistical examination reveals no relation between the sizes of gravid females and full-term embryos.

As in other species of Squalus, both left and right ovaries are functional in this species. Monthly size frequency distributions of ovarian eggs are presented in Fig. 4. From January to February, ova were small measuring $5-7 \mathrm{~mm}$ in diameter.

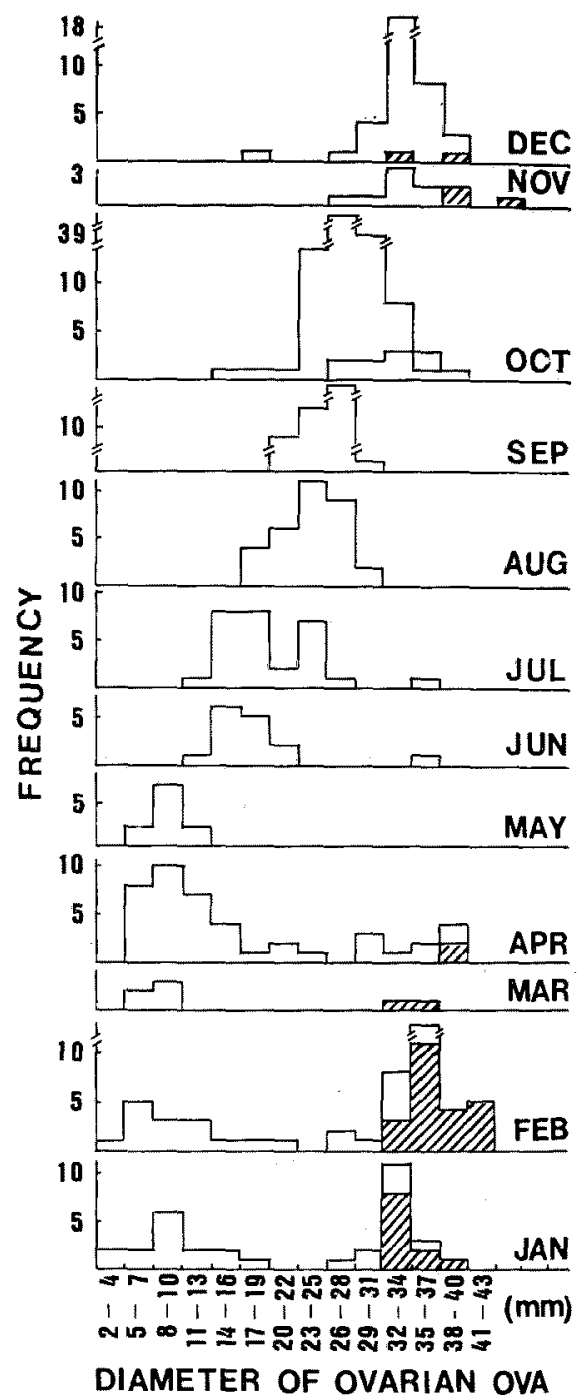

Fig. 4. Monthly diameter frequency distributions of ovarian ova in $S$. japonicus collected from Nagasaki. Shaded histogram indicates ova immediately before ovulation.

They increased in size with month and grew to $29-44 \mathrm{~mm}$ in diameter during the period from November to April. Since ova more than $28 \mathrm{~mm}$ in diameter seemed to be near-ovulation, we estimate that ovulation occurred between October and April with a peak in January and February. Therefore, it may be concluded from the above evidence that it takes about one year of development from the formation to its ovulation. There was no large difference in the size at ovulation between the two regions. The diameter of ova of nearovulation in Choshi was $35-44 \mathrm{~mm}$ in diameter. 
Thus, eggs in ovaries show an increase in diameter with growth of embryos in the uterus.

\section{Litter Size}

Litter size is shown by size group for each region in Table 3. As stated earlier, it is clear that the size range of gravid females in the two regions was quite different. Only $740-759 \mathrm{~mm}$ and 760 $779 \mathrm{~mm}$ size groups overlap. Litter size ranged from 2 to 8 in both regions. However, the modal number differed by region, that is 4 in specimens from Nagasaki and 6 in those from Choshi. Most gravid females from Nagasaki carried 3 to 5 embryos whereas the bulk of gravid females from Choshi carried 4 to 6 embryos. The average litter size was 3.9 in Nagasaki and 5.3 in Choshi.

No marked difference was observed in the number of embryos in the left and right uteri. Most adult females carried an equal number of embryos in both uteri or possessed one more embryo in one side than in the other. Of 303 gravid females from Nagasaki only 4 specimens carried two more embryos in the right uterus than in the left.

Litter size varied with size of gravid females. For instance, females of the $600-619 \mathrm{~mm}$ size group carried 2 to 4 embryos with an average of 2.9 in Nagasaki whereas those of the $720-739 \mathrm{~mm}$ size group carried 3 to 5 embryos with an average of 4.4 (Table 3). Litter size of the former group was about two-thirds as large as that of the latter. The same was true of litter size of the specimens from Choshi, although the difference was not as large as that in Nagasaki. Thus, litter size increased with the length of the parent. Analysis of covariance for the relation between total length of the parent and litter size showed no significant difference at the $5 \%$ level in the slopes and adjusted means between the two regions (Table 4-a). This indicates that the relationship between total length and litter size is not different by region if the size range of each population is extrapolated or interpolated. In fact, however, the fecundity differed greatly by region due to the large difference in the size range of mature females between the two regions. The same relation was observed between total length and number of ova per adult female between the two regions (Table 4-b).

The number of ovarian eggs per adult female is shown by size group for each region in Table 5 . It ranged from 2 to 9 in Nagasaki and 4 to 12 in Choshi. The modal number was 4 in Nagasaki and 6 in Choshi. There was a great difference in the average number of ova between Nagasaki (4.4) and Choshi (6.4). Thus, the number of ova increased with the length of the parent similar to litter size. However, the average number of ova was always greater than that of embryos within each size group. Analysis of covariance showed a significant difference in the adjusted means be-

Table 3. Litter size of specimens collected from Nagasaki and Choshi

\begin{tabular}{|c|c|c|c|c|c|c|c|c|c|c|c|c|c|c|c|c|}
\hline \multirow{3}{*}{$\begin{array}{l}\text { Total length } \\
\text { of mother } \\
(\mathrm{mm})\end{array}$} & \multicolumn{16}{|c|}{ Number of embryos } \\
\hline & \multicolumn{8}{|c|}{ Nagasaki } & \multicolumn{8}{|c|}{ Choshi } \\
\hline & 2 & 3 & 4 & 5 & 6 & 7 & 8 & Average & 2 & 3 & 4 & 5 & 6 & 7 & 8 & Average \\
\hline $580-599$ & & 3 & & & & & & 3.00 & & & & & & & & \\
\hline $600-619$ & 4 & 5 & 3 & & & & & 2.93 & & & & & & & & \\
\hline $620-639$ & 11 & 8 & 15 & & & & & 3.12 & & & & & & & & \\
\hline $640-659$ & 4 & 12 & 19 & 3 & & & & 3.55 & & & & & & & & \\
\hline $660-679$ & 4 & 16 & 30 & 7 & & & 1 & 3.78 & & & & & & & & \\
\hline $680-699$ & 3 & 8 & 27 & 15 & 4 & & & 4.16 & & & & & & & & \\
\hline $700-719$ & 3 & 12 & 29 & 22 & 4 & 1 & & 4.21 & & & & & & & & \\
\hline $720-739$ & & 3 & 12 & 4 & 4 & & & 4.39 & & & & & & & & \\
\hline $740-759$ & & & 3 & 3 & & & & 4.50 & & & 1 & 1 & & & & 4.50 \\
\hline $760-779$ & & & & 1 & & & & 5.00 & & 2 & & 1 & & & & 3.67 \\
\hline $780-799$ & & & & & & & & & & & 2 & 2 & 3 & & & 5.14 \\
\hline $800-819$ & & & & & & & & & 1 & 1 & 2 & & 4 & & 1 & 5.00 \\
\hline $820-839$ & & & & & & & & & & & 2 & 2 & 3 & 4 & 1 & 6.00 \\
\hline $840-859$ & & & & & & & & & 1 & & & 3 & 3 & & & 5.00 \\
\hline $860-879$ & & & & & & & & & & 1 & 1 & 1 . & 2 & & 1 & 5.33 \\
\hline $880-899$ & & & & & & & & & & & & & 1 & 2 & 1 & 7.00 \\
\hline $900-919$ & & & & & & & & & & & & 1 & & & & 5.00 \\
\hline Subtotal & 29 & 67 & 138 & 55 & 12 & 1 & 1 & & 2 & 4 & 8 & 11 & 16 & 6 & 4 & \\
\hline Total average & & & & & & & & 3.81 & & & & & & & & 5.35 \\
\hline
\end{tabular}


Table 4. Covariance analysis tables for pairs of samples by places and items. Fa and $\mathrm{Fb}$ are the variance ratios to test the significance of the regression coefficient and adjusted means respectively

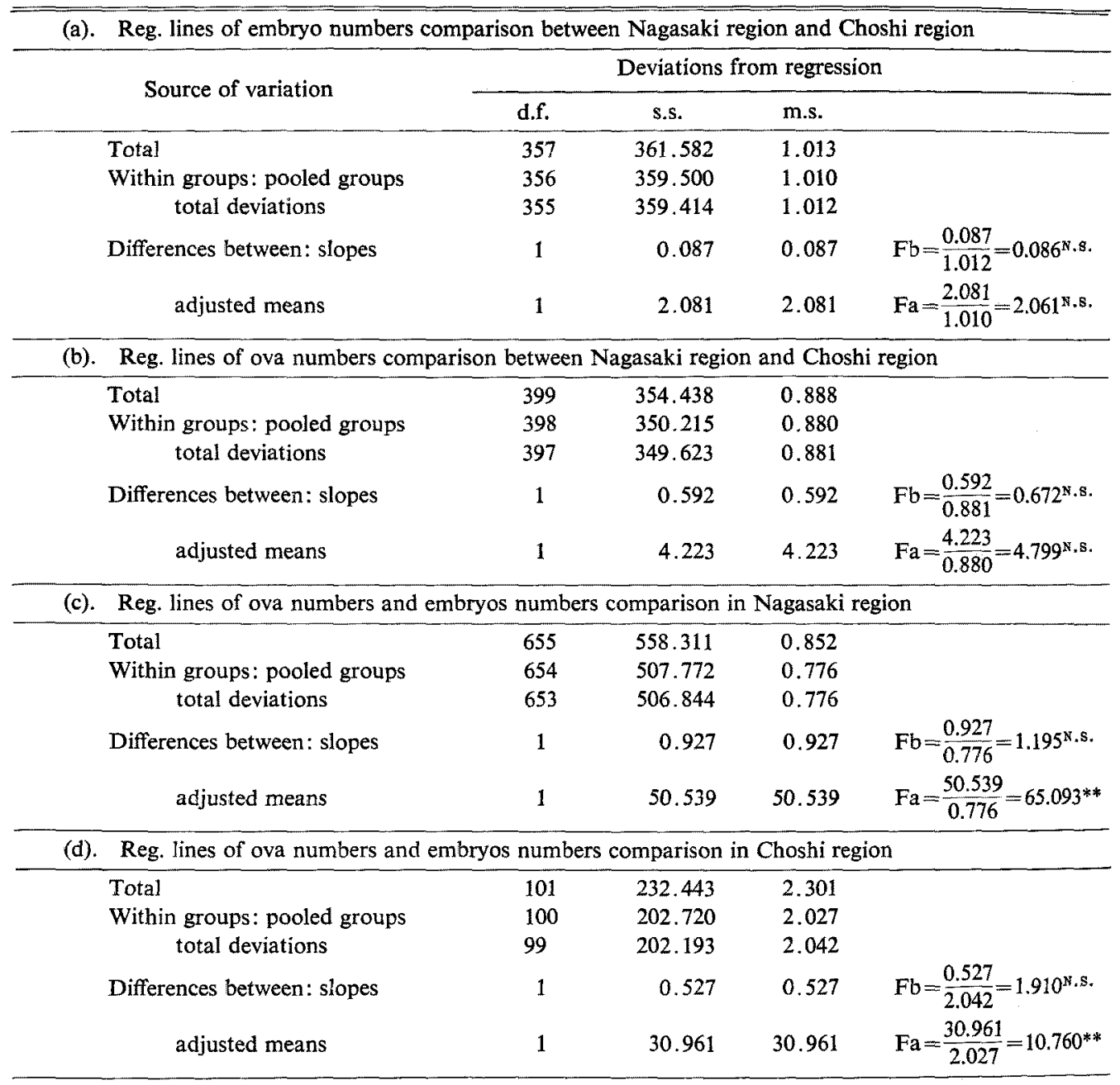

** Significant at the $1 \%$ level.

tween the number of ova and embryos (Table 4-c, 4-d). This means that ova outnumber embryos in the entire range of adult females.

\section{Sex Ratio}

Identification of sex of embryos was possible in individuals between the sizes of 70 to $80 \mathrm{~mm}$ in total length through the presence of claspers. Accordingly, the sex ratio treated here refers to that of embryos over $80 \mathrm{~mm}$. The sex ratio of embryos differed by litter. For instance, two females possessed one female and 4 male embryos in the uteri. In another cases, two specimens carried 7 male and one female embryos. As a whole the ratio of male to female embryos was 443: 408 in Nagasaki and 43: 59 in Choshi. Statistically, the null hypothesis that the ratio was $1: 1$ could not be rejected for both regions at the $5 \%$ significance level, according to $\chi^{2}$ test. Thus, it is concluded that the sex ratio of embryos is about $1: 1$ as a whole in the two regions, although it differs largely by litter.

\section{Discussion}

It is clear that there were great differences in the size at maturity and the maximum size for both sexes between specimens from Nagasaki and Choshi 